\title{
Relationship between Amazon biomass burning aerosols and rainfall over the La Plata Basin
}

\author{
G. Camponogara ${ }^{1}$, M. A. F. Silva Dias ${ }^{1}$, and G. G. Carrió ${ }^{2}$ \\ ${ }^{1}$ Instituto de Astronomia, Geofísica e Ciências Atmosféricas da Universidade de São Paulo, Brazil \\ ${ }^{2}$ Department of Atmospheric Sciences of Colorado State University, USA
}

Correspondence to: G. Camponogara (glauberic@gmail.com)

Received: 18 July 2013 - Published in Atmos. Chem. Phys. Discuss.: 11 September 2013

Revised: 11 March 2014 - Accepted: 14 March 2014 - Published: 5 May 2014

\begin{abstract}
High aerosol loads are discharged into the atmosphere by biomass burning in the Amazon and central Brazil during the dry season. These particles can interact with clouds as cloud condensation nuclei $(\mathrm{CCN})$ changing cloud microphysics and radiative properties and, thereby, affecting the radiative budget of the region. Furthermore, the biomass burning aerosols can be transported by the low-level jet (LLJ) to the La Plata Basin, where many mesoscale convective systems (MCS) are observed during spring and summer. This work proposes to investigate whether the aerosols from biomass burning may affect the MCS in terms of rainfall over the La Plata Basin during spring. Aerosol effects are very difficult to isolate because convective clouds are very sensitive to small environment disturbances; for that reason, detailed analyses using different techniques are used. The binplot, 2-D histograms and combined empirical orthogonal function (EOF) methods are used to identify certain environmental conditions with the possible effects of aerosol loading. Reanalysis 2, TRMM-3B42 and AERONET data are used from 1999 up to 2012 during September-December. The results show that there are two patterns associated with rainfallaerosol interaction in the La Plata Basin: one in which the dynamic conditions are more important than aerosols to generation of rain; and a second one where the aerosol particles have a more important role in rain formation, acting mainly to suppress rainfall over the La Plata Basin. However, these results need further investigation to strengthen conclusions, especially because there are limitations and uncertainties in the methodology and data set used.
\end{abstract}

\section{Introduction}

During the dry season, high concentrations of aerosol particles from biomass burning associated with human activities (mainly agricultural practices and deforestation) have been documented in the Amazon and central Brazil (Artaxo et al., 2002; Freitas et al., 2005; Martins et al., 2009). These aerosols can act as cloud condensation nuclei $(\mathrm{CCN})$, potentially changing the cloud microphysics as well as the radiative properties and lifetime of clouds (Martins et al., 2009) affecting the Amazon's radiative budget (Lin et al., 2006).

It is well known that aerosols can affect the environment through scattering and absorption of solar radiation (direct effect) and interactions with cloud microphysics (indirect effect). The Intergovernmental Panel on Climate Change (IPCC, 2007) indicates that the uncertainty in aerosol effects on clouds is large compared to other forcings due to human activities. High concentrations of aerosol can modify cloud droplet distribution, increasing droplet concentration while keeping an approximately constant liquid water content (Twomey, 1974). The reduction in cloud droplet size changes the precipitation efficiency and causes an increase in cloud liquid water content and lifetime of the clouds (Albrecht, 1989).

Comparing polluted and clear atmospheres, Rosenfeld (1999) observed that high concentrations of aerosol suppress warm precipitation and that clouds present colder tops than in clear conditions. Through numerical modeling, van den Heever et al. (2006) observed that an increase in aerosol concentration causes an increase in updraft velocity due to latent heat release by condensation. They verify an increase in amounts of rain associated with an increase in GCCN (giant 
cloud condensation nuclei) and IFN (ice-forming nuclei), whereas an increase in $\mathrm{CCN}$ concentration causes a rainfall decrease. High $\mathrm{CCN}$ concentrations can also increase ice particle numbers (van den Heever et al., 2006) and, thereby, lighting (Albrecht et al., 2011). In the Amazon Basin, Andreae et al. (2004) indicate that clouds formed in regions with a heavy load of biomass burning aerosols have droplet spectra with different properties than clouds formed in clear environments.

Convective clouds are very sensitive to small environmental differences; therefore, it is very difficult to isolate aerosol effects from observations (Wall, 2013). According to Khain et al. (2008), precipitation can be affected by drop condensation and ice deposition (generation), and drop evaporation and ice sublimation (loss), where these variables are perturbed by wind shear, moisture, instability, aerosol, etc. However, atmospheric conditions (e.g., dynamic processes) tend to be more important than aerosol for rainfall production (Jones and Christopher, 2010).

Morales et al. (2010) characterized meteorological conditions associated with thunderstorm and non-thunderstorm days over the city of São Paulo and investigated the pollution influence on them. The thunderstorms were basically regulated by dynamical and thermodynamic characteristics while aerosols did not show any significant effect. On the other hand, Albrecht et al. (2011) observed that large-scale and local environmental thermodynamics processes favored the development of intense thunderstorms over the Amazon at the end of the dry season, with no apparent effect of aerosol loading. During the wet season, however, thunderstorms were preferably observed in periods of high $\mathrm{CCN}$ concentrations.

Tao et al. (2007) showed aerosol effects on three different deep convective cloud systems. These authors concluded that higher aerosol concentration can either favor or disfavor the precipitation process, depending on atmospheric conditions. Fan et al. (2007) found that rain delay is more sensitive to relative humidity than to aerosol concentrations and only under conditions of significant moisture can the aerosols significantly change convection and rain rate. Numerical studies focused on isolated deep convective clouds performed by Fan et al. (2009) show that in the case of strong wind shear, generally, aerosols suppress convection. This effect is more important in humid air than dry air. Fan et al. (2009) also observed an enhancement in convection by enhanced aerosol concentrations under weak wind shear until an optimum aerosol concentration is reached.

In the present study, the sensitivity of rainfall to aerosol is examined for the La Plata Basin. This basin is the fifth-largest hydrographic basin in the world and the second-largest on the continent, covering Uruguay, Brazil, Argentina, Paraguay and Bolivia. It has a very large hydroelectric potential, with several plants placed on its rivers. Located in one of most densely populated regions in South America, the La Plata Basin sustains domestic consumption and agricultural activi- ties and, thereby, represents an important economic factor for the region.

Figure 1 from Silva Dias et al. (2009) (cf. Durkee and Mote, 2010) shows the geographical and seasonal distribution of mesoscale convective systems (MCS) in South America. It may be seen that there is a greater number of MCS during the austral spring and summer over South America, mainly over Paraguay, northern Argentina and southern Brazil. These systems are large cumulunimbus clusters with lifecycles from hours to days and can cause floods, heavy rainfall and severe weather (Velasco and Fritsch, 1987; Fritsch and Forbes, 2001). Zipser et al. (2006) reports that the MCS in the La Plata Basin are seen as the most intense in the world.

Observational studies from Marengo et al. (2002) and Salio et al. (2007) show a narrow flow north of the La Plata Basin and east of the Andes, with a maximum wind speed at an altitude of approximately $2000 \mathrm{~m}$, known as a low-level jet (LLJ). The LLJ is responsible for carrying large heat and moisture content from the Amazon Basin southward toward the La Plata Basin, feeding the convective systems that develop in the region. Furthermore, Freitas et al. (2005) suggest that the LLJ can transport aerosols from biomass burning in the Amazon and central Brazil to the La Plata Basin in the dry season (austral winter and spring). Thus, in austral spring, the MCS develop under high aerosol loading conditions and, consequently, may be affected by these particles.

Figure 2 is a schematic illustration of the present work context. The climatologies for aerosol optical depth (AOD) at $440 \mathrm{~nm}$ for the Rio Branco and Alta Floresta stations and rainfall for Asunción, Santa Maria and Buenos Aires are shown. The AOD and rainfall are retrieved by AERONET and TRMM-3B42, respectively. Ji Paraná, Cuiabá, Santa Cruz and Campo Grande (in red) are also AOD stations; their climatological graphics are not shown in Fig. 2, but their data are used in this study. AOD stations show high values between July and December (dry season) with peaks, in September, of about 1.0 for Rio Branco and 1.5 for Alta Floresta. These high values are due to biomass burning activity (Artaxo et al., 2002) and are eventually transported via LLJ to the La Plata Basin (Freitas et al., 2005). Significant amounts of rain are observed in Asunción for most of the year (less in July-September) and for the whole year in Buenos Aires and Santa Maria. Indeed, the aerosols from the biomass burning region may potentially affect the hydrologic balance of the La Plata Basin. However, the question that arises is, if aerosols from biomass burning in the Amazon and central Brazil affect the evolution of MCS in the La Plata Basin, how important is the impact on precipitation? This work proposes to address this question using available data from AERONET and TRMM-3B42 and the NCAR/DOE reanalysis. Section 2 describes the data and method of analysis; in Sect. 3 a case study is presented to illustrate the large-scale setup of a typical MCS in the region. Results and discussion of the available 


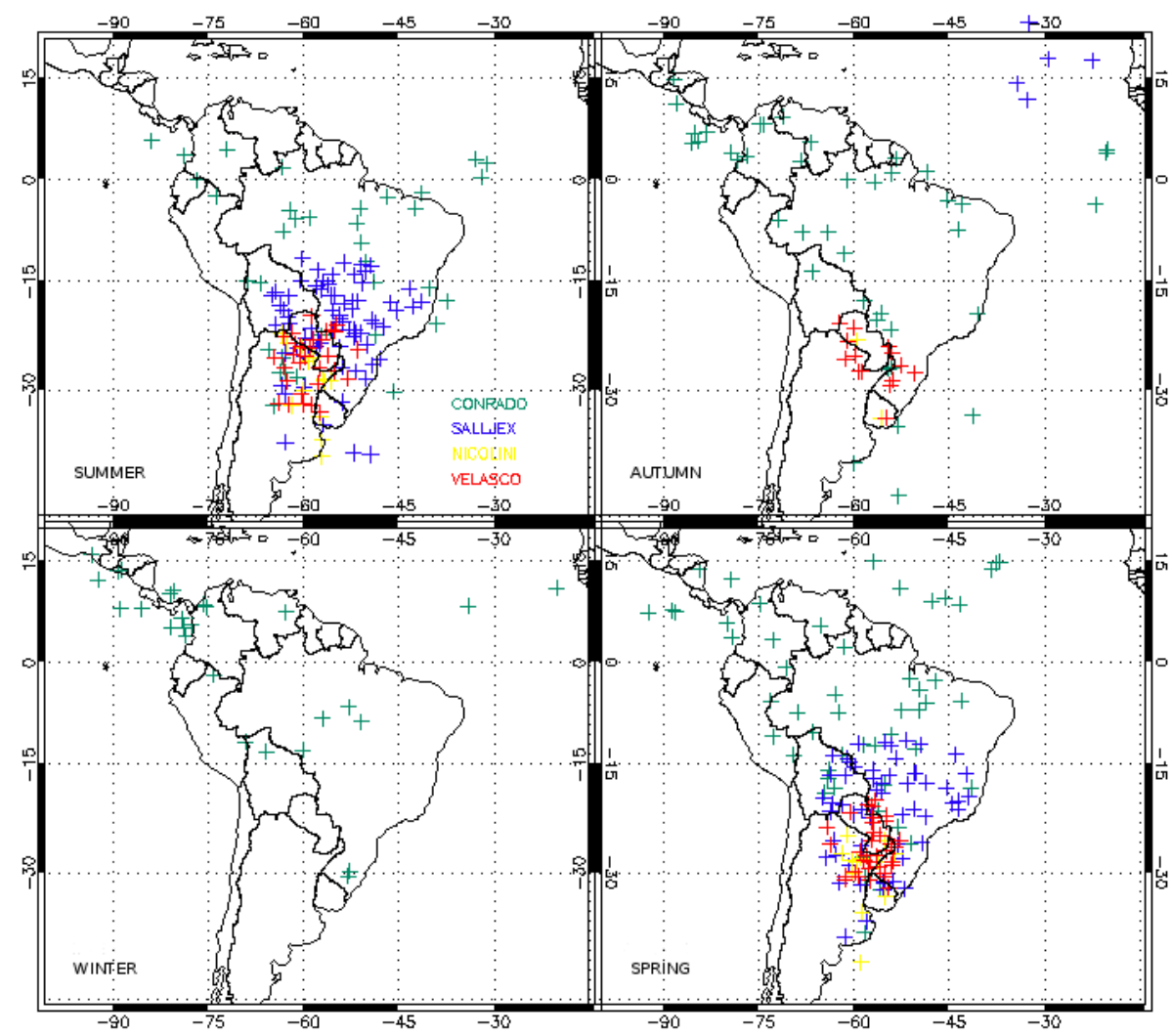

Fig. 1. Climatological distribution of MCS over South America for each season (Silva Dias et al., 2009). The figure is a compilation of results from Velasco and Fritsch (1987), Conforte (1997), Torres and Nicolini (2002), and Salio et al. (2007). The MCS observed during SALLJEX (Vera et al., 2006) are indicated.

time series and conclusions are presented in Sects. 4 and 5, respectively.

\section{Data and methods}

Three different methods will be presented in an attempt to examine the aerosol effects on rainfall over the La Plata Basin. As described below, this study uses reanalysis to characterize the dynamic and thermodynamic environment, precipitation estimates from satellites and AOD data from AERONET. The data period extends from 1999 to 2012 and the focus is on the dry season and the beginning of the wet season (i.e., September through December).

\subsection{Reanalysis 2}

Reanalysis 2 data from NCEP-DOE (National Center for Environmental Prediction - Department of Energy) is used in order to provide large-scale information about the $\mathrm{La}$ Plata Basin. These data are an updated version of NCEPNCAR (National Center for Atmospheric Research) reanalysis, with improvements to the forecast model and data assimilation system (Kanamitsu et al., 2002). It has an updated 6-hourly global analysis series from 1979 to the present and $2.5^{\circ} \times 2.5^{\circ}$ grid spacing and is available from http://www. esrl.noaa.gov/psd/data/gridded/data.ncep.reanalysis $2 . h t m l$.

Winds at $850 \mathrm{hPa}$ are used to define the circulation associated with convective systems. The field of vertical $\mathrm{p}$ velocity $\omega$ at $500 \mathrm{hPa}$ is used to indicate the dynamic forcing, with negative $\omega$ indicating upward vertical motion favoring the development of clouds, while positive values indicate subsidence, in principle inhibiting clouds. The mean relative humidity between 700 and $500 \mathrm{hPa}(\mathrm{RH})$ is chosen as an indicator of mid-level moisture in the environment. These variables, vertical p velocity and relative humidity, are averaged over all grid points in the blue box (Fig. 3). In order to simplify the nomenclature of these variables, they will just be called $\omega$ (areal average of vertical p velocity at $500 \mathrm{hPa}$ ) and RH (areal average of mean relative humidity).

\subsection{TRMM-3B42}

The spatial and time variations of rainfall have been obtained from a TRMM (Tropical Rainfall Measuring Mission) satellite, generated by the 3B42 algorithm version 7 . These gridded rainfall estimates have been available since 1998 with a $3 \mathrm{~h}$ temporal resolution and $0.25^{\circ} \times 0.25^{\circ}$ spatial resolution 


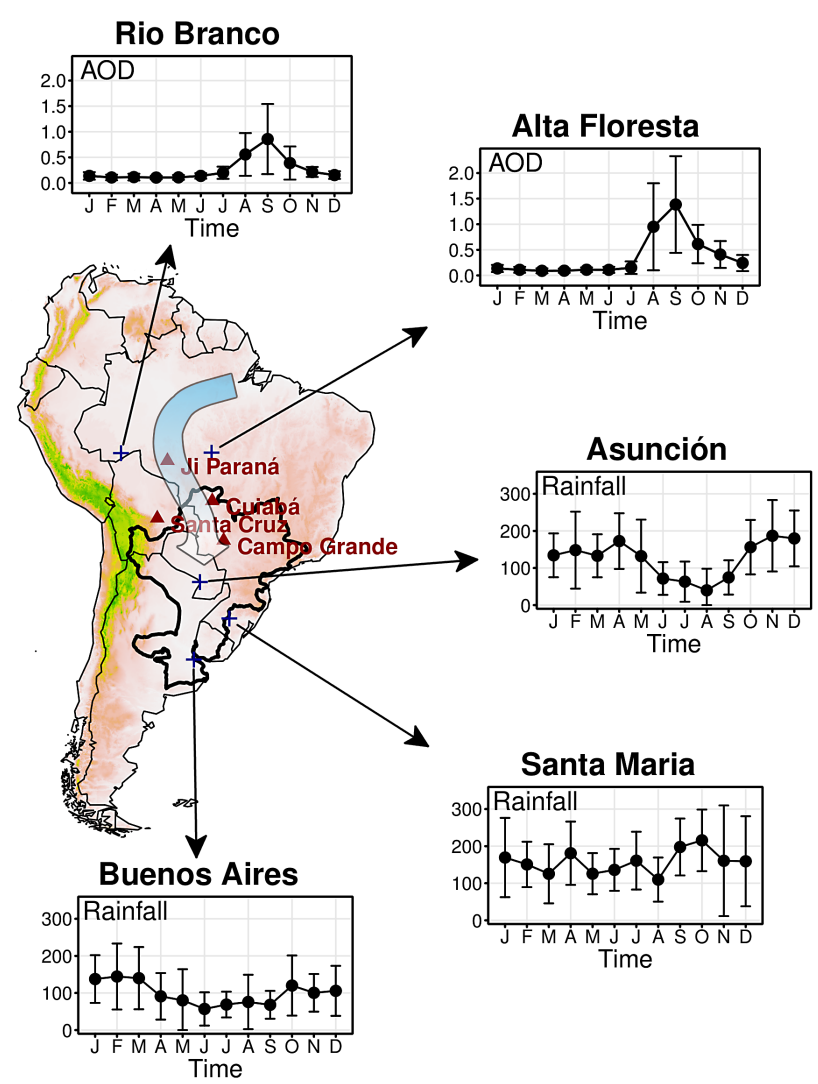

Fig. 2. Schematic illustration of this work context. The graphics are climatologies of AOD for the Rio Branco and Alta Floresta AERONET stations, and rainfall estimates from TRMM-3B42 for the cities of Asunción, Santa Maria and Buenos Aires. Ji Paraná, Cuiabá, Santa Cruz, and Campo Grande AOD stations are located in red.

covering global latitudes from $50^{\circ} \mathrm{S}$ to $50^{\circ} \mathrm{N}$ (http://trmm. gsfc.nasa.gov/3b42.html). According to Su et al. (2008), the precipitation estimates from TRMM-3B42 detect most of the daily precipitation events over the La Plata Basin, although they tend to overestimate heavy precipitation. Rainfall rate in $\mathrm{mm} \mathrm{day}^{-1}$ and the percentage of rainy grid points over the blue rectangle (rainfall fraction) were computed. A rainy grid point is defined when rainfall rate $>0.2 \mathrm{~mm} \mathrm{~h}^{-1}$. Areal averages over all grid points in the blue box region (Fig. 3) are computed for rainfall rate; only cases with values above $1 \mathrm{~mm}$ day $^{-1}$ are considered to be rain events. In the next sections the areal average of rainfall rate of the blue box is hereafter referred to as RR.

\subsection{AERONET}

We used AOD data provided by AERONET (Aerosol Robotic Network), described by Holben et al. (1998) and coordinated by NASA (National Aeronautic Spatial Agency). AERONET is a global network of sunphotometers that has monitored AOD and aerosol optical properties, under clear

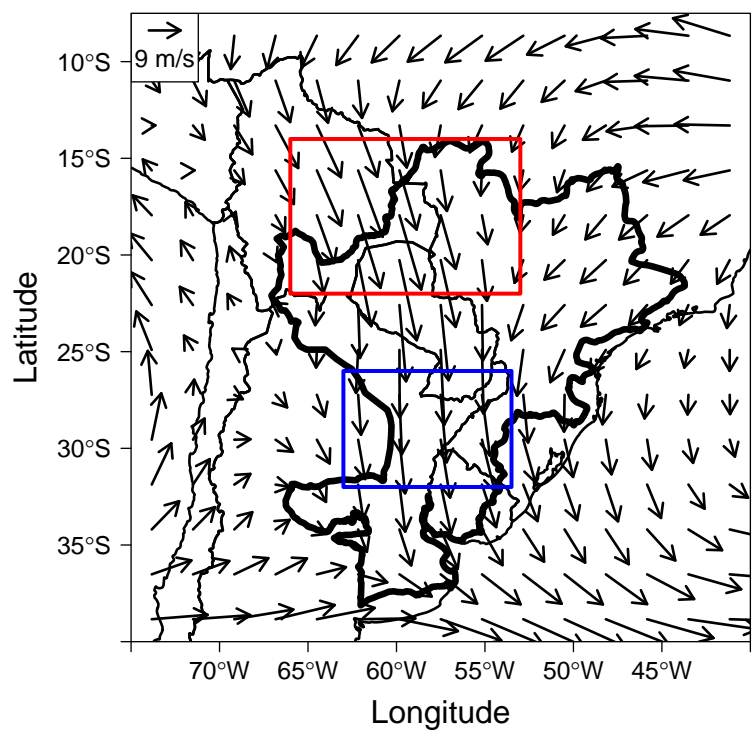

Fig. 3. Mean wind of north flow cases identified by the filtering method. The blue box represents the study area, the red box is an auxiliary region for the filter and the thick black contour delimits the La Plata Basin.

sky conditions during the day from directed sun measurements, since 1993. The level 2 product of daily AOD for the wavelength of $440 \mathrm{~nm}$ has been used for the sunphotometers at Alta Floresta, Ji Paraná, Rio Branco, Santa Cruz, Campo Grande and Cuiabá. These locations are indicated in Fig. 2.

AOD has been used as proxy for aerosol concentration following the work of Guyon et al. (2003). They showed that the Amazon Basin biomass burning causes the AOD increases with an increased Ångström coefficient, indicating that in polluted conditions the fine mode of aerosols predominantly contributes to the aerosol concentration.

\subsection{Filtering}

The main assumption of this work is that aerosol from biomass burning is advected from the Amazon and central Brazil to the La Plata Basin under north wind conditions (Freitas et al., 2005). Figure 3 shows the average wind field for of all north wind cases from 1999 to 2012 in the transition from the dry to wet seasons; the blue box represents the area under study in the La Plata Basin where rainfall and aerosol relationships are investigated. The red box is located between the blue box and the biomass burning region. A north wind case is defined when the areal average of the meridional wind component over both red and blue rectangles is negative. The cases with wind direction between $30^{\circ}$ and $90^{\circ}$ over the blue rectangle are discarded to avoid sample contamination from other aerosol sources (e.g., from southeastern Brazil). A further condition to accept a north wind case is that minimum rainfall $(<3 \mathrm{~mm}$ as areal average over the red box) is observed between the source region and the study region, so 
that cases where aerosols would be removed by wet deposition before arriving at the blue rectangle are not considered.

The aerosol travel time from the origin to the destination is taken into account by defining a time lag as the time period (in days) that aerosols take to travel from the origin station to the La Plata Basin. For each rain event, lagged correlations between RR and AOD retrieved from 1 up to 5 days before the rain event were computed.

The higher absolute value of lagged correlation for each station is used to define the lag as an indicator of the optimal time interval between aerosol sources and the blue rectangle region (i.e., there is a time lag for each AERONET station). The time lags were also calculated based on average wind at $850 \mathrm{hPa}$ and the distance between the origin and destination. The results (not shown) were similar, suggesting that the lags were adequate for relating AOD measurements from the Amazon to rainfall in the La Plata Basin.

\subsection{Binplot}

Binplot is an easy tool for exploring the effect of low and high aerosol loadings on the rainfall. This method basically consists in averaging rainfall rate between a bin range of AOD (in this case, 0.1). Then for each AOD range, the average rainfall rate was calculated and plotted for each of the AERONET stations.

\subsection{2-D histograms}

This method is similar to the binplot, but now, besides AOD intervals, intervals of $\omega$ and rainfall fraction will be considered. The rainfall fraction is defined as the percentage of grid points with rainfall rate $>0.2 \mathrm{~mm} \mathrm{~h}^{-1}$. For each interval of $\omega$, representing a given dynamic pattern, the aerosol effects are investigated.

\subsection{Combined EOF}

According to the methodology contained in Wilks (2006), the combined empirical orthogonal function (EOF) analysis has been used to determine patterns in the joint variation of AOD, rainfall rate, $\omega$ and relative humidity. This procedure has been used as another way of detecting aerosol effects with similar synoptic patterns. EOF calculation was then divided into four steps:

1. A matrix of data was built as

$$
\left[\begin{array}{llll}
\mathrm{AOD}_{1} & \mathrm{RR}_{1} & \omega_{1} & \mathrm{RH}_{1} \\
\mathrm{AOD}_{2} & \mathrm{RR}_{2} & \omega_{2} & \mathrm{RH}_{2} \\
\vdots & \vdots & \vdots & \vdots \\
\mathrm{AOD}_{n} & \mathrm{ARR}_{n} & \omega_{n} & \mathrm{RH}_{n}
\end{array}\right]
$$

where $n$ corresponds to the number of cases selected;
2. The matrix was normalized by subtracting each column from its average and dividing by its standard deviation;

3. The covariance matrix was determined from the normalized matrix;

4. The combined EOF was calculated through the eigen function from $\mathrm{R}$ software (http://www.r-project.org) that uses the LAPACK (Linear Algebra PACKage) routines.

The results from the aforementioned statistical analysis are described after an overall presentation of a case study along with the general features associated with MCS in the La Plata Basin.

\section{A case study}

An MCS that occurred on 12 September 2007 is used to illustrate the motivation of this work. Figure 4 shows AOD values for September 2007 for each station in the Amazon and central Brazil. High AOD values are associated with intense biomass burning (Artaxo et al., 2002), with peaks around 5 for Alta Floresta, 4 for Ji Paraná, 3 for Rio Branco and 2 for other stations (Santa Cruz had no measurements in this month). Looking for days closer to 12 September, it is possible to observe AOD values over 2 for all stations. Then on 12 September, winds from the north indicate a case of transport of high aerosol loadings from the Amazon and central Brazil to the south. This condition provides an environment with high aerosol concentration where the MCS was formed.

Satellite images are shown in Fig. 5 for 05:00, 06:45, 10:15 and 14:00 UTC. These images reveal the formation of MCS up to the mature stage; some isolated cells are formed during the first hours and begin to grow and organize, generating a large cloud cluster over northeastern Argentina that reached the mature stage at approximately 14:45 UTC. This system reached brightness temperatures below $-70^{\circ} \mathrm{C}$ and, according to the precipitation estimate from TRMM-3B42, it generated a $6 \mathrm{~mm} \mathrm{day}^{-1}$ area average and a maximum of $14.4 \mathrm{~mm} \mathrm{~h}^{-1}$ (both over the blue rectangle).

Wind and relative humidity at $850 \mathrm{hPa}$, mean $700-500 \mathrm{hPa}$ $\mathrm{RH}$ (shaded) and $\omega$ at $500 \mathrm{hPa}$ (contour), and wind and divergence at $200 \mathrm{hPa}$ are given in Fig. 6. A moist region with $\mathrm{RH}$ above $50 \%$ is apparent, slightly to the east from a moisture flow observed at $850 \mathrm{hPa}$ (Fig. 6a). The $\omega$ field is close to zero over the MCS location, in other words, a neutral condition at $500 \mathrm{hPa}$. The moisture flow from the north is apparent along with a wind convergence at low levels and upper level divergence at $200 \mathrm{hPa}$. This condition favors convection, as discussed by Salio et al. (2007). The question posed is whether systems like this may have been affected by aerosols coming from the north and intruding in low to middle levels into the MCS. The next section will investigate if the aerosols may 


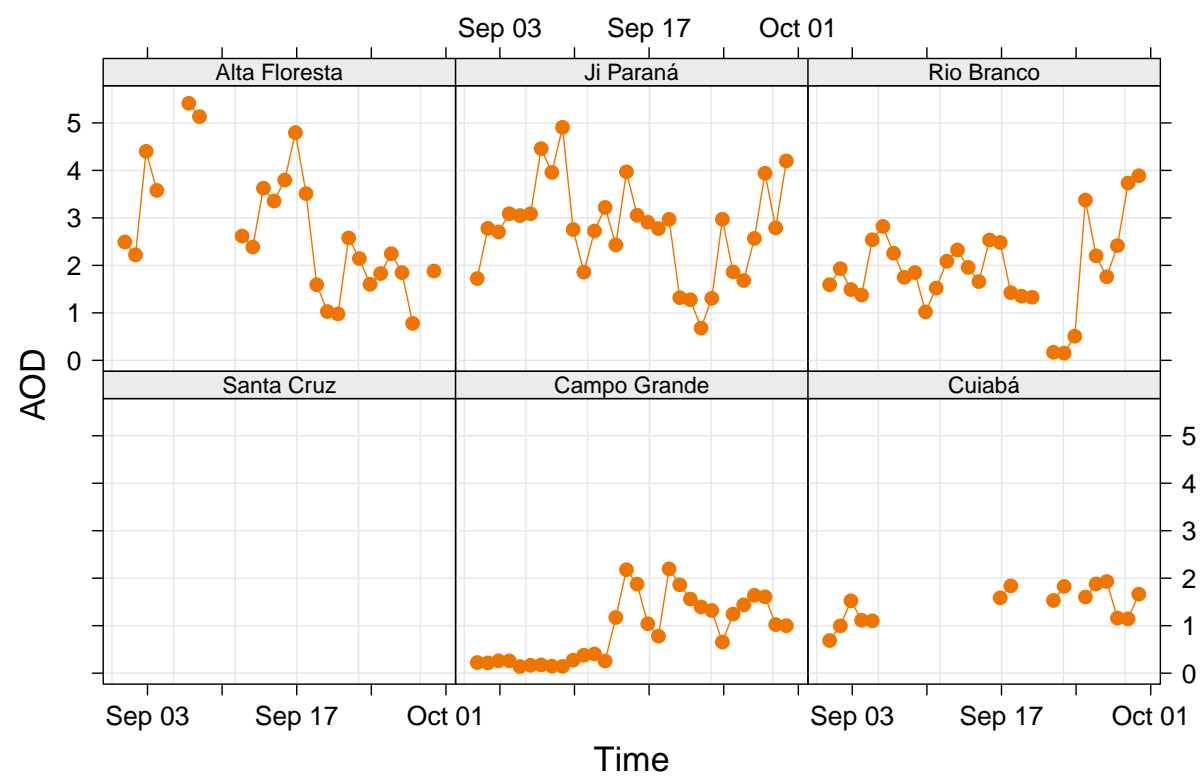

Fig. 4. Daily AOD during September 2007 from the AERONET stations. There were no measurements from the Santa Cruz station for this period.

cause any detectable effect on precipitation over the La Plata Basin, thus influencing the hydrology of the region.

\section{Results and discussion}

Comparisons between aerosols and rainfall have been made by considering the best correlated time lag between the path from the biomass burning region to the La Plata Basin, as described in Sect. 2.4. The total number of analyzed cases is 150 from Alta Floresta, 33 from Ji Paraná, 109 from Rio Branco, 45 from Santa Cruz, 78 from Campo Grande and 78 from Cuiabá. Figure 7 shows the rainfall rate as a function of AOD. It can be seen that rainfall decreases as AOD increases, which means higher aerosol load is associated with lower precipitation. This pattern occurs at all stations and it is more significant for AOD below 1, but is it really related to aerosol loads? Or may it occur due to another forcing? Another feature of Fig. 7 is an indication of a bimodal distribution of rainfall with AOD; the reasons for that are unknown at this point. The local maxima may be due to different environmental conditions associated with rainfall. We further examine this in the following paragraphs when we separate rainfall according to the dynamic forcing represented by $\omega$.

Figure 8 shows the average rainfall rate (shaded boxes) as a function of rainfall fraction and AOD. Differences in rainfall rates between rainfall fraction and AOD ranges are immediately apparent. Below $40 \%$ there is no contrast between the shaded boxes; in other words, it is not possible to detect the aerosol effect. For values above $40 \%$, a strong contrast between the boxes can be seen, indicating a possible impact of aerosols on rainfall. In other words, the effect of aerosol loading on rainfall is statistically evident in systems capable of generating large areal precipitation over the basin through a 2-D histogram method. However, patterns cannot be identified clearly, probably because there are other dominant forcings.

Dynamics is one of most important forcings to generate rain and, for this reason, it is very difficult to recognize aerosol effects that are usually secondary. In this context, dynamic patterns were separated using the two-dimensional histograms (similar to Fig. 8). Figure 9 shows the rainfall rate as a function of $\omega$ and AOD. $\omega$ (the vertical $p$ velocity at $500 \mathrm{hPa}$ ) is used to identify the large-scale dynamic forcing. Large values of negative $\omega$ are associated with enhanced upper motion that favors the widespread development of rainfall. In the absence of this forcing, low values of $\omega$ represent cases where the large-scale dynamics does not force rainfall. Differences between strong and weak $\omega$ (below and above $-0.25 \mathrm{~Pa} \mathrm{~s}^{-1}$, respectively) are easily observed for all stations. AOD dominates the precipitation for low $\omega$ values; conversely, vertical velocity dominates the precipitation under high $\omega$ values. Thus, aerosol effects are dominant under weak dynamic forcing conditions, inhibiting rainfall. Another feature of Fig. 9 is a bimodal distribution (like in Fig. 7) associated with large rainfall amounts and intense dynamic forcing. This pattern explains the nature of the two modes identified in Fig. 7 that are due to the large-scale upward motion.

Combined EOFs were calculated in another attempt to observe the aerosol effect and reinforce the previous results. The combined EOF analysis is used to identify variability patterns from a group of variables. In other words, the eigenvectors detect linear relationships between AOD, RR, $\omega$, and 


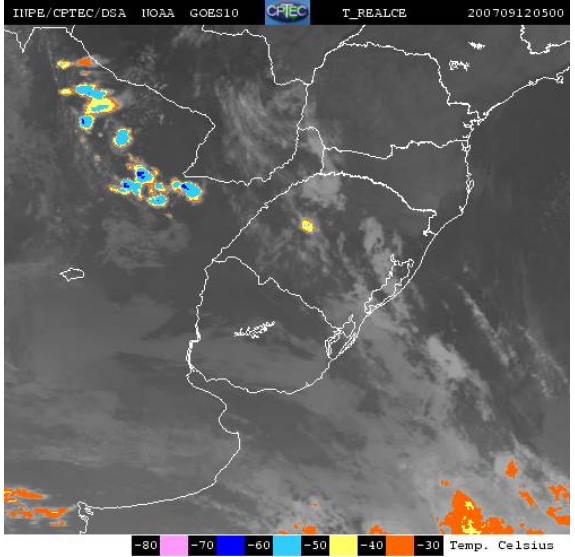

(a) 05:00 UTC

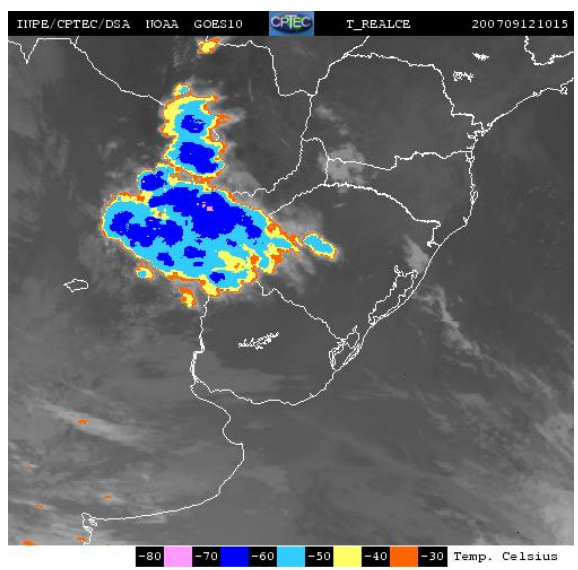

(c) 10:15 UTC

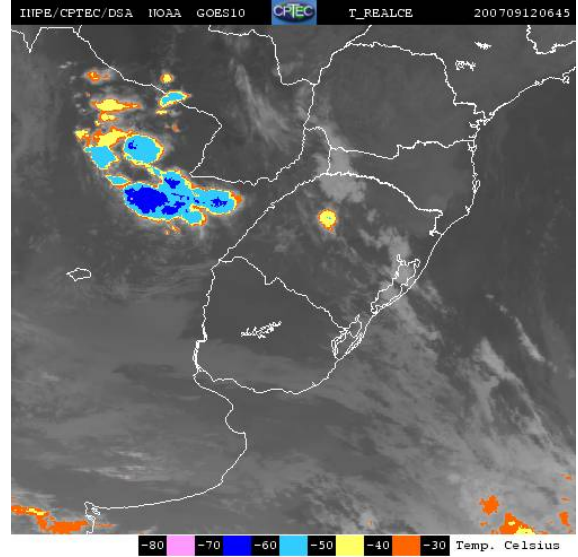

(b) $06: 45$ UTC

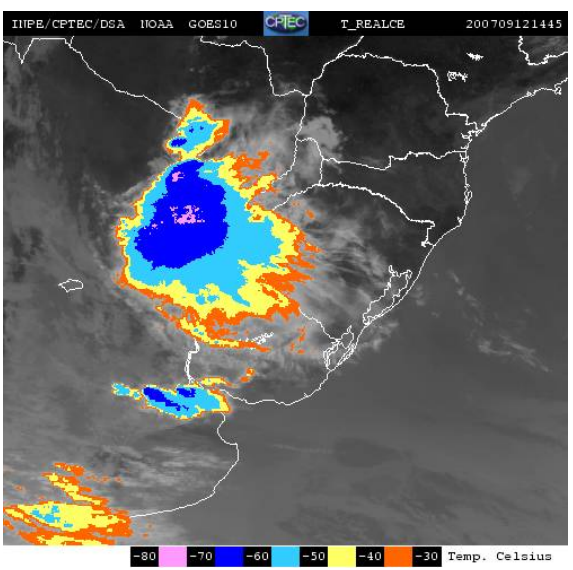

(d) 14:45 UTC

Fig. 5. Enhanced infrared satellite images from GOES 10 for an MCS evolution on 12 September 2007 over the La Plata Basin. Colors indicate infrared temperatures. (a) 05:00 UTC, (b) 06:45 UTC, (c) 10:15 UTC, and (d) 14:45 UTC.

RH. Table 1 shows the variance explained by the first and second eigenvectors and the total explained by these two. The first EOF explains around $43 \%$ of the variance of the data set for all AOD stations and the second EOF $31 \%$; together these eigenvectors represent more than $70 \%$ of the data variance explained. The other two EOFs are not shown since they explain a lower portion of the variance. Satellite images for the cases detected by the EOF time series were examined (not shown). It was observed that about $70 \%$ of selected rain events are associated with MCS. The other $30 \%$ are basically related to cold fronts and extratropical cyclones with embedded convective systems.

EOFs and their respective components AOD, RR, $\omega$ and RH for each AOD station (in colors) are shown in Fig. 10; values represent perturbations with respect to the average. Looking at $e_{1}$, it is possible to verify that this eigenvector detects a pattern with small AOD anomalies and large anomalies of RR, $\omega$ and RH, reflecting a pattern basically independent of AOD. The physical interpretation of the first eigen-
Table 1. Variance explained by the first and second EOFs and the variance explained by these two EOFs for each AOD station for all selected cases (see Sect. 2.4) during the months of September, October, November and December of 1999-2012.

\begin{tabular}{lccc}
\hline & $R_{1}^{2}(\%)$ & $R_{2}^{2}(\%)$ & $R_{1}^{2}+R_{2}^{2}$ \\
\hline Alta Floresta & 41 & 31 & 72 \\
Ji Paraná & 43 & 30 & 73 \\
Rio Branco & 42 & 34 & 76 \\
Santa Cruz & 45 & 30 & 75 \\
Campo Grande & 41 & 31 & 72 \\
Cuiabá & 43 & 30 & 73 \\
\hline
\end{tabular}

vector is that stronger large-scale upward motion and moister mid-level atmosphere are associated with larger amounts of rainfall. For a moister mid-level environment, the entrainment into the cloud generates less evaporation, thus potentially affecting the rainfall production. 


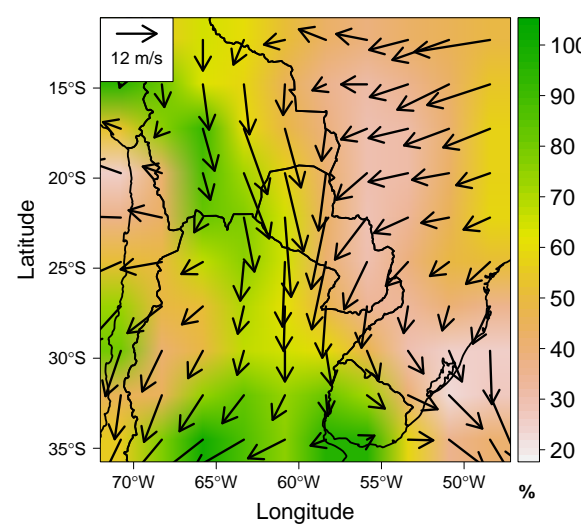

(a)

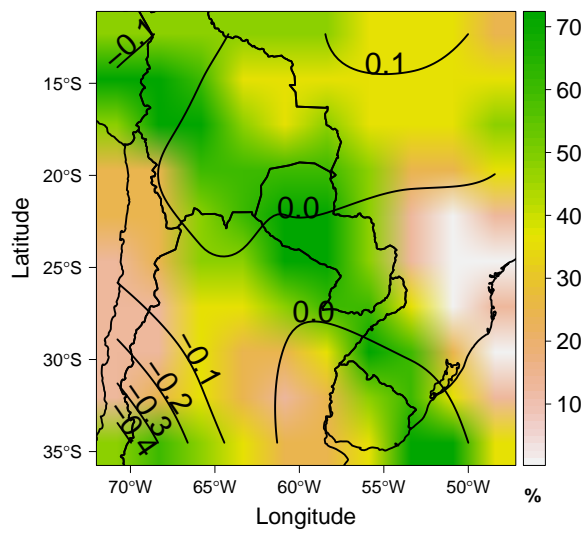

(b)

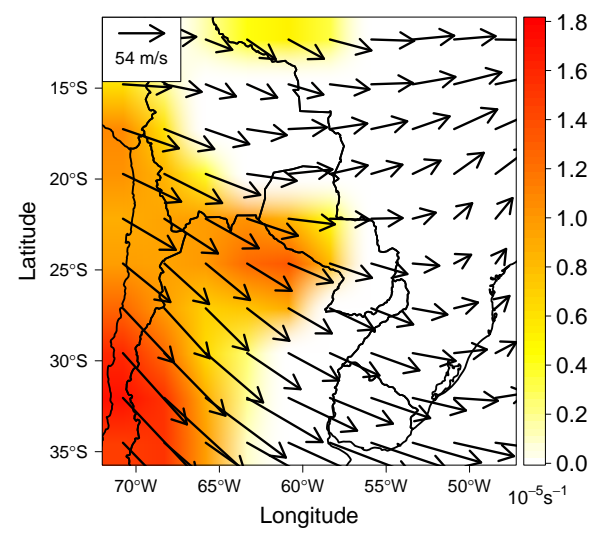

(c)

Fig. 6. Large-scale fields on 12 September 2007 at 06:00 UTC: (a) wind and relative humidity at $850 \mathrm{hPa}$; (b) mean 700-500 hPa relative humidity (shaded) and $\omega$ at $500 \mathrm{hPa}$ (contour); (c) wind and divergence at $200 \mathrm{hPa}$.

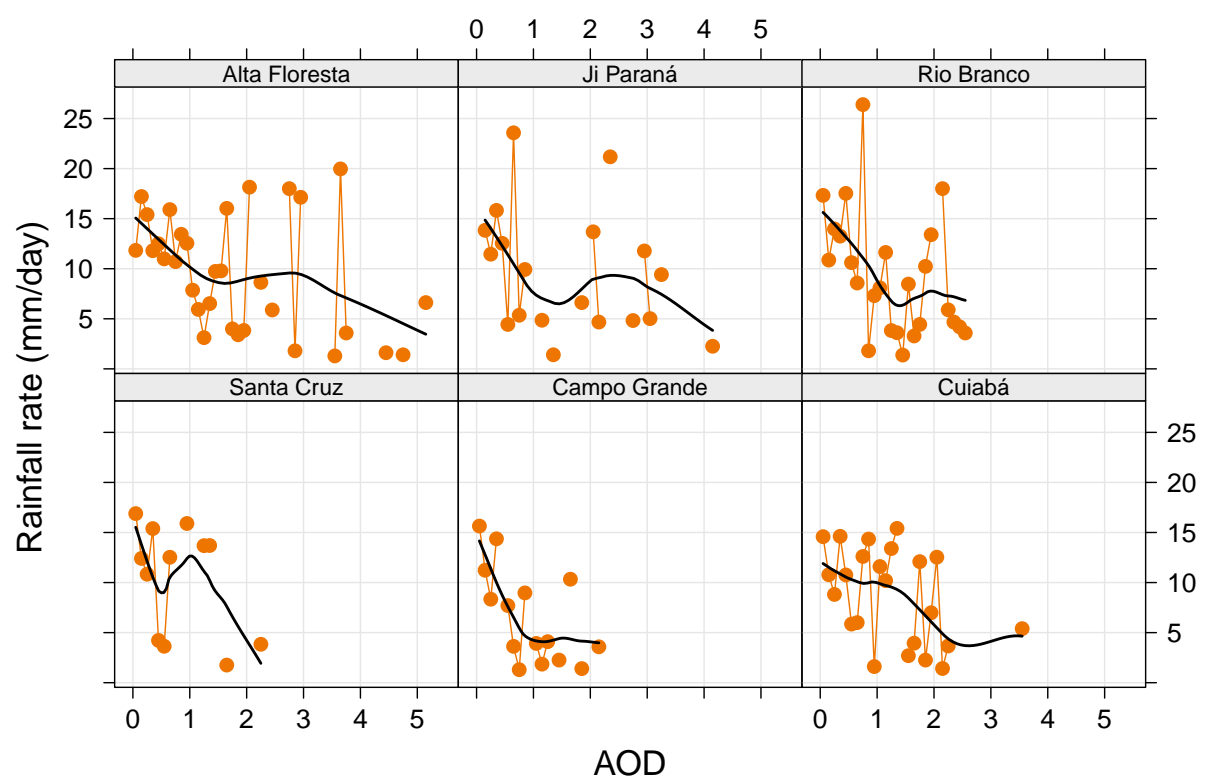

Fig. 7. Rainfall rate binned by the AOD range of 0.1 for each AERONET station for all selected cases (see Sect. 2.4) during the months of September, October, November and December of 1999-2012. 


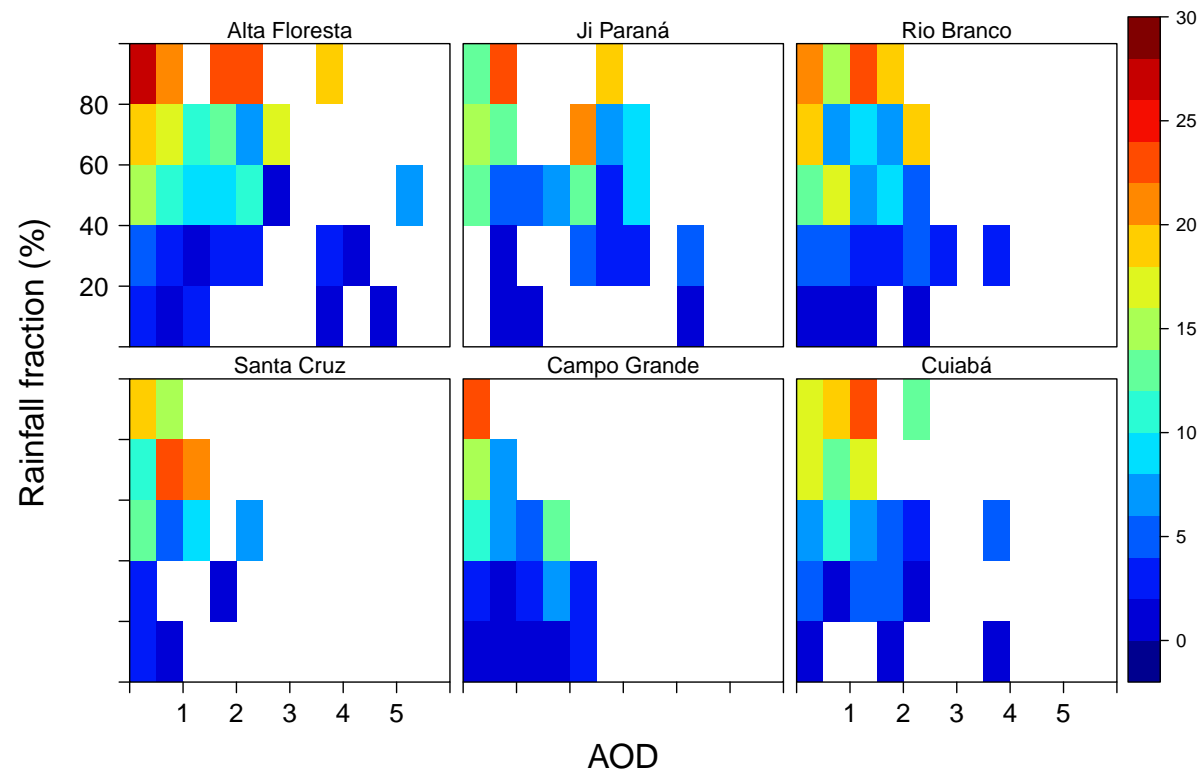

Fig. 8. Two-dimensional histogram of the average rainfall rate for each AERONET station for all selected cases (see Sect. 2.4) during the months of September, October, November and December of 1999-2012. Colors indicate average rainfall rate for each bin of rainfall fraction and AOD.

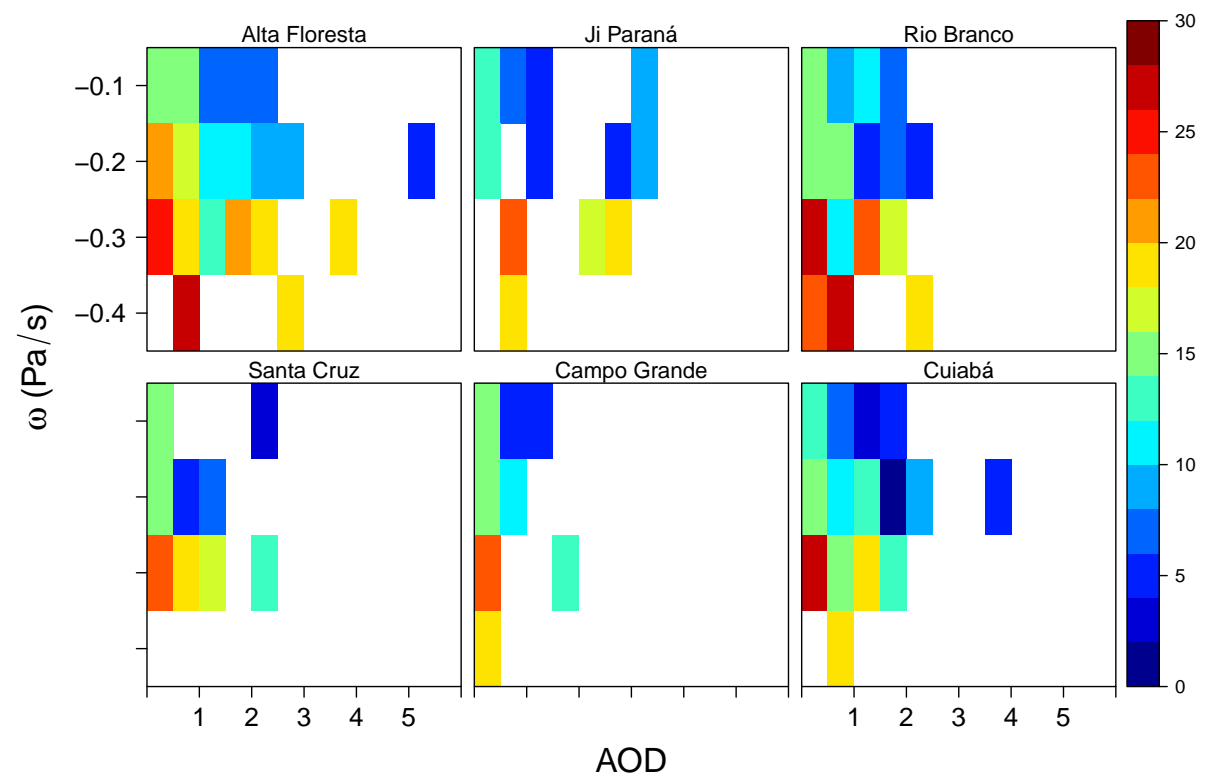

Fig. 9. Two-dimensional histogram of the average rainfall rate for each AERONET station for all selected cases (see Sect. 2.4) during the months of September, October, November and December of 1999-2012. Colors indicate average rainfall rate for each bin of $\omega$ and AOD.

The second EOF detects large positive anomalies of AOD associated with large negative anomalies in rainfall for small anomalies of $\omega$ and RH. For this pattern, the interpretation is that $\omega$ and $\mathrm{RH}$ are average, while large AOD is associated with rainfall suppression.

The results from the EOF analysis agree with Figs. 7 and 9 in that the dynamic component appears as the main rainfall forcing and the aerosol loading as the second one. The first
EOF is related to dynamic forcing, whereas the second EOF seems to represent the aerosol forcing. Jones and Christopher (2010) also used EOF analysis to identify possible interactions between aerosols and precipitation in the Amazon Basin. Their results also detected two patterns, one related to atmospheric conditions favorable to rainfall and the other linked to the aerosol forcing, and associated with rainfall inhibition. 


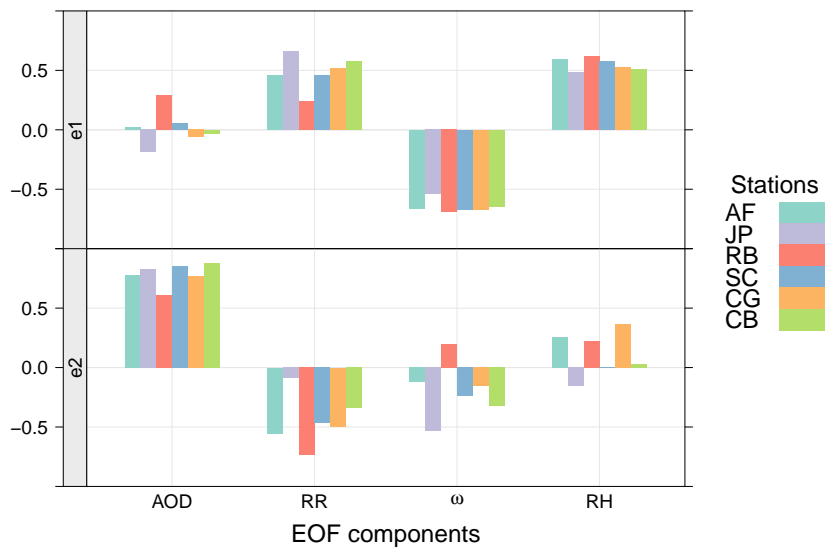

Fig. 10. EOFs and their AOD, RR, $\omega$, and RH components for each AERONET station for all selected cases (see Sect. 2.4) during the months of September, October, November and December of 19992012. Colors indicate the stations of Alta Floresta (AF), Ji Paraná (JP), Rio Branco (RB), Santa Cruz (SC), Campo Grande (CG), and Cuiabá (CB).

\section{Conclusions}

Previous works (Andreae et al., 2004; Freitas et al., 2005) indicate the aerosol can be transported by the LLJ from the Amazon and central Brazil biomass burning regions to the La Plata Basin. Based on these studies we used three statistical tools in an attempt to isolate aerosol effects from biomass burning on rainfall over the La Plata Basin. The period analyzed was 1999-2012 during the dry season and the beginning of the wet season (September-December) using data from AERONET, TRMM-3B42 and reanalysis 2.

Generally, results show that high aerosol concentrations tend to suppress precipitation for the three statistical methods used. It was only possible to detect the aerosol effect on rainfall fractions above $40 \%$ (through 2-D histograms). When absolute values of $\omega$ are large, aerosol effects are not detected. However, for $\omega>-0.25 \mathrm{~Pa} \mathrm{~s}^{-1}$ (weak dynamic forcing), high aerosol concentrations tend to suppress rainfall.

A bimodal distribution was observed between rainfall and AOD through the binplot (Fig. 7) and a 2-D histrogram (Fig. 9). This means that two local maxima of rainfall rate were present under two different AOD regimes. These peaks are generally associated with strong dynamic forcing. In other words, stronger large-scale upward motion causes larger rainfall amounts, which contrasts with the aerosol effects that are associated with rainfall suppression.

The first two patterns from the EOF analysis explain more than $70 \%$ of the data variance, corresponding to about $43 \%$ for the first EOF and $31 \%$ for the second one. The first eigenvector identified the dynamic forcing in which strong vertical velocities represented by $\omega$, moist atmosphere at medium levels and aerosol concentration near the average cause rain above the average. $e_{2}$ detected the aerosol forcing in which high aerosol loadings in a slightly moist atmosphere and below average $\omega$ were associated with rainfall suppression. These results show that the dynamic component is the main forcing for rain production, while aerosols have a role in inhibiting the rainfall under weak large-scale forcing.

The aerosol rain suppression in MCS is certainly very complex. Simpler cases such as single cloud studies indicate possible processes to take into account. However, the dynamics of large MCS involve multiscale interactions (from cloudscale to mesoscale to large-scale) over a period of several hours. In the particular case of the MCS over the La Plata Basin, the system is apparently affected in its cloud microphysics, with a steady flow of aerosol coming from biomass burning regions to the north. Unfortunately, there are limitations and uncertainties in the statistic tools and data used here that could potentially affect the conclusions. Thus, it is necessary to address this issue further with other tools, such as numerical experimentation, to understand the mechanisms involved and to reduce the uncertainty in the results.

Acknowledgements. This research was supported by Coordenação de Aperfiçoamento de Pessoal de Nível Superior (CAPES) and São Paulo Research Foundation (FAPESP), grant no. 2012/08115-9.

Edited by: G. Feingold

\section{References}

Albrecht, B. A.: Aerosols, cloud microphysics, and fractional cloudiness, Science, 245, 1227-1230, 1989.

Albrecht, R. I., Morales, C. A., and Silva Dias, M. A. F.: Electrification of precipitating systems over the Amazon: Physical processes of thunderstorm development, J. Geophys. Res., 116, D08209, doi:10.1029/2010JD014756, 2011.

Andreae, M. O., Rosenfeld, D., Artaxo, P., Costa, A. A., Frank, G. P., Longo, K. M., and Silva Dias, M. A. F.: Smoking rain clouds over the Amazon, Science, 303, 1337-1342, 2004.

Artaxo, P., Martins, J. V., Yamasoe, M. A., Procópio, A. S., Pauliquevis, T. M., Andreae, M. O., Guyon, P., Gatti, L. V., and Leal, A. M. C.: Physical and chemical properties of aerosols in the wet and dry season in Rondônia, Amazonia, J. Geophys. Res., 107, 8081-8095, 2002.

Conforte, J. C.: Um estudo de complexos convectivos de mesoescala sobre a América do Sul, Ph.D. thesis, INPE, 112 pp., 1997.

Durkee, J. D. and Mote, T. L.: A climatology of warm-season mesoscale convective complexes in subtropical South America, Int. J. Climatol., 30, 418-431, 2010.

Fan, J., Zhang, R., Li, G., and Tao, W.-K.: Effects of aerosols and relative humidity on cumulus clouds, J. Geophys. Res.-Atmos., 112, D14204, doi:10.1029/2006JD008136, 2007.

Fan, J., Yuan, T., Comstock, J. M., Ghan, S., Khain, A., Leung, L. R., Li, Z., Martins, V. J., and Ovchinnikov, M.: Dominant role by vertical wind shear in regulating aerosol effects on deep convective clouds, J. Geophys. Res.-Atmos., 114, D22206, doi:10.1029/2009JD012352, 2009. 
Freitas, S. R., Longo, K. M., Silva Dias, M. A. F., Silva Dias, P. L., Chatfield, R., Prins, E., Artaxo, P., Grell, G. A., and Recuero, F. S.: Monitoring the transport of biomass burning emissions in South America, Environ. Fluid Mech., 5, 135-167, 2005.

Fritsch, J. M. and Forbes, G. S.: Mesoscale Convective Systems, Severe Convective Storms, Meteorol. Mon., 28, 323-356, 2001.

Guyon, P., Graham, B., Beck, J., Boucher, O., Gerasopoulos, E., Mayol-Bracero, O. L., Roberts, G. C., Artaxo, P., and Andreae, M. O.: Physical properties and concentration of aerosol particles over the Amazon tropical forest during background and biomass burning conditions, Atmos. Chem. Phys., 3, 951-967, doi:10.5194/acp-3-951-2003, 2003.

Holben, B. N, Eck, T. F, Slutsker, I., Tanré, D., Buis, J. P., Setzer, A., Vermote, E., Reagan, J. A, Kaufman, Y. J., Nakajima, T., Lavenu, F., Jankowiak, I., and Smirnov, A.:AERONET-A federated instrument network and data archive for aerosol characterization, Remote Sens. Environ., 16, 1-16, doi:10.1016/S00344257(98)00031-5, 1998.

IPCC: Report of the 26th session of the IPCC. Bangkok, 30 April-4 May 2007. Intergovernmental Panel on Climate Change, Geneva, Switzerland, 2007.

Jones, T. A. and Christopher, S. A.: Statistical properties of aerosol-cloud-precipitation interactions in South America, Atmos. Chem. Phys., 10, 2287-2305, doi:10.5194/acp-10-22872010, 2010.

Kanamitsu, M., Ebisuzaki, W., Woollen, J., Yang, S.-K., Hnilo, J. J., Fiorino, M., and Potter, G. L.: Ncep-doe amip-ii reanalysis (r-2), B. Am. Meteorol. Soc., 83, 1631-1644, 2002.

Khain, A. P., BenMoshe, N., and Pokrovsky, A.: Factors determining the impact of aerosols on surface precipitation from clouds: An attempt at classification, J. Atmos. Sci., 65, 1721-1748, 2008.

Lin, J. C., Matsui, T., Pielke Sr, R., and Kummerow, C.: Effects of biomass-burning-derived aerosols on precipitation and clouds in the Amazon Basin: A satellite-based empirical study, J. Geophys. Res., 111, D19204, doi:10.1029/2005JD006884, 2006.

Marengo, J. A., Douglas, M. W., and Silva Dias, P. L.: The South American low-level jet east of the Andes during the 1999 LBATRMM and LBA-WET AMC campaign, J. Geophys. Res., 107, 8079, doi:10.1029/2001JD001188, 2002.

Martins, J. A., Silva Dias, M. A. F., and Gonçalves, F. L. T.: Impact of biomass burning aerosols on precipitation in the Amazon: A modeling case study, J. Geophys. Res., 114, D02207, doi:10.1029/2007JD009587, 2009.

Morales, C. A. R, da Rocha, R. P., and Bombardi, R.: On the development of summer thunderstorms in the city of São Paulo: mean meteorological characteristics and pollution effect, Atmos. Res., 96, 477-488, doi:10.1016/j.atmosres.2010.02.007, 2010.
Rosenfeld, D.: TRMM observed first direct evidence of smoke from forest fires inhibiting rainfall, Geophys. Res. Lett., 26, 31053108, 1999.

Salio, P., Nicolini, M., and Zipser, E. J.: Mesoscale convective systems over southeastern South America and their relationship with the South American Low Level Jet, Mon. Weather Rev., 135, 1290-1309, 2007.

Silva Dias, M. A. F., Rozante, J. R., and Machado, L. A. T.: Complexos Convectivos de Mesoescala na América do Sul, Tempo e Clima no Brasil, 181-194, 2009.

Su, F., Hong, Y., and Lattenmaier, D. P: Evaluation of TRMM Multisatellite Precipitation Analysis (TMPA) and its utility in hydrologic prediction in the La Plata Basin, J. Hydrometeorol., 9, 622640, 2008.

Tao, W. K., Li, X., Khain, A., Matsui, T., Lang, S., and Simpson, J.: Role of atmospheric aerosol concentration on deep convective precipitation: Cloud-resolving model simulations, J. Geophys. Res., 112, D24S18, doi:10.1029/2007JD008728, 2007.

Torres, J. C. and Nicolini, M.: A composite mesoscale convective systems over southern South America and its relationship to lowlevel jet events, in: Conference on south american low-level jet, CD-ROM, Santa Cruz de la Serra, 2002.

Twomey, S.: Pollution and the planetary albedo, Atmos. Environ., 8, 1251-1256, 1974.

van den Heever, S. C., Carrió, G. G., Cotton, W. R., DeMott, P. J., and Prenni, A. J.: Impacts of nucleating aerosol on Florida storms. Part I: Mesoscale simulations, J. Atmos. Sci., 63, 17521775, 2006.

Velasco, I. and Fritsch, J. M.: Mesoscale convective complexes in the Americas, J. Geophys. Res., 92, 9591-9613, 1987.

Vera, C., Baez, J., Douglas, M., Emmanuel, C. B., Marengo, J., Meitin, J., Nicolini, M., Nogues-Paegle, J., Paegle, J., Penalba, O., Salio, P., Saulo, C., Silva Dias, M. A. F., Silva Dias, P., and Zipser, E. J.: The South American Low-Level Jet experiment, B. Am. Meteorol. Soc., 87, 63-77, 2006.

Wall, C. L.: The impact of aerosols on convective clouds: a global perspective, Ph.D. thesis, The University of Utah, 2013.

Wilks, D. S.: Statistical methods in the atmospheric sciences, Academic press, Elsevier, Burlington, 2nd Edn., 2006.

Zipser, E. J., Cecil, D. J., Liu, C., Nesbitt, S. W., and Yorty, D. P.: Where are the most intense thunderstorms on Earth?, B. Am. Meteorol. Soc., 87, 1057-1072, 2006. 